\title{
Red Man Syndrome with Oral Vancomycin: A Case Report
}

\author{
Fray Arroyo-Mercado, Aleksandr Khudyakov, Gurasees S. Chawla, \\ Onix Cantres-Fonseca, Isabel M. McFarlane* \\ Department of Medicine, State University of New York, Downstate Medical Center, Brooklyn, NY 11203 USA \\ *Corresponding author: Isabel.McFarlane@downstate.edu
}

Received December 15, 2019; Revised January 20, 2019; Accepted January 27, 2019

\begin{abstract}
Red Man syndrome (RMS) occurs with the rapid infusion of intravenous (IV) vancomycin. RMS induced by oral vancomycin has been the focus of a limited number of case reports. We present a case of a 75-year-old female admitted with severe Clostridium difficile colitis who received oral vancomycin and by the second day of therapy, she developed flushing, erythema, and pruritus involving the face, neck and upper torso. Oral vancomycin was immediately withheld, and diphenhydramine was initiated. Clinical improvement was apparent 24 hours after discontinuation of oral vancomycin. Our case adds to the published literature on this rare clinical entity that should be considered when severe colitis patients prescribed oral vancomycin, as part of the standard of care, develop the typical signs and symptoms of RMS.
\end{abstract}

Keywords: Vancomycin, red man syndrome, colitis, oral vancomycin, intravenous vancomycin, histamine release

Cite This Article: Fray Arroyo-Mercado, Aleksandr Khudyakov, Gurasees S. Chawla, Onix Cantres-Fonseca, and Isabel M. McFarlane, "Red Man Syndrome with Oral Vancomycin: A Case Report." American Journal of Medical Case Reports, vol. 7, no. 1 (2019): 16-17. doi: 10.12691/ajmcr-7-1-5.

\section{Introduction}

Red Man Syndrome (RMS) is an idiopathic pseudo-allergic drug reaction that may develop after administration of vancomycin [1]. It is frequently observed with infusion of vancomycin, not commonly observed with its oral administration [1]. The patient shows signs and symptoms of an allergic reaction, but without any classic allergy immunologic mechanism [2]. Common symptoms include flushing, wheezing, erythema, pruritus, hypotension and muscle spasms. This phenomenon is postulated to be related to the rate of infusion of vancomycin [3]. Other medications that have been associated with RMS include ciprofloxacin, rifampicin, teicoplanin, and amphotericin B [2]. Nevertheless, severe colonic inflammation may disrupt the mucosal barrier predisposing to the oral absorption of vancomycin.

\section{Case Presentation}

A 75-year-old female with history asthma, diabetes and breast cancer status post chemotherapy was admitted for abdominal pain, watery diarrhea, and subjective fevers for four days. She had received antibiotics for pneumonia two weeks prior. On physical exam, she was febrile $\left(103^{\circ}\right)$, tachycardic (128 beats/min) and blood pressure was 100/70 mmHg. Abdominal exam revealed diminished bowel sounds and diffuse abdominal tenderness, without rebound or guarding. Laboratory data showed white blood cell count of 16,000 cells/ul with $2 \%$ bands, lactic acid was $7 \mathrm{mg} / \mathrm{dL}$, chemistries were otherwise normal. Abdominal CT revealed diffuse wall thickening and fat stranding. Stool sample for C. difficile toxin was positive. Given the recent chemotherapy and antibiotic course, the initial concern was typhilitis or C. difficile colitis. Treatment was initiated with IV fluids, oral vancomycin 250 mg every 6 hours, IV metronidazole and ciprofloxacin. Typhlitis was excluded due to the lack of neutropenia; thus, ciprofloxacin was discontinued after one dose. Following the 7th dose of oral vancomycin the patient developed flushing, erythema, and pruritus of the face, neck and upper torso (Figure 1). The adverse reaction resolved after the discontinuation of oral vancomycin and administration of diphenhydramine (Figure 2). Oral metronidazole was continued for 14 days and patient had an uneventful recovery. The patient recalled having a previous episode of RMS with IV vancomycin, which had resolved after decreasing the infusion rate.

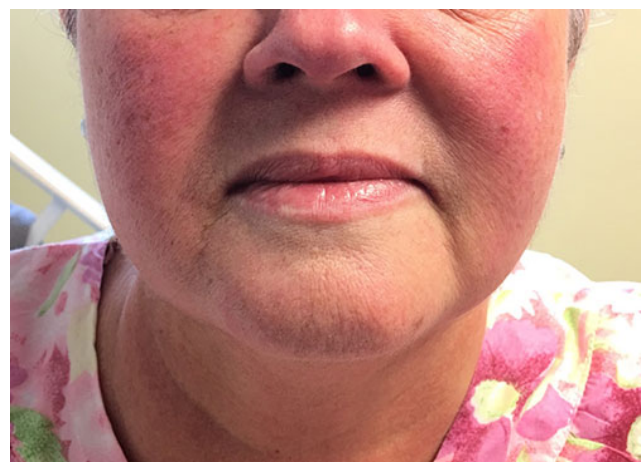

Figure 1. 


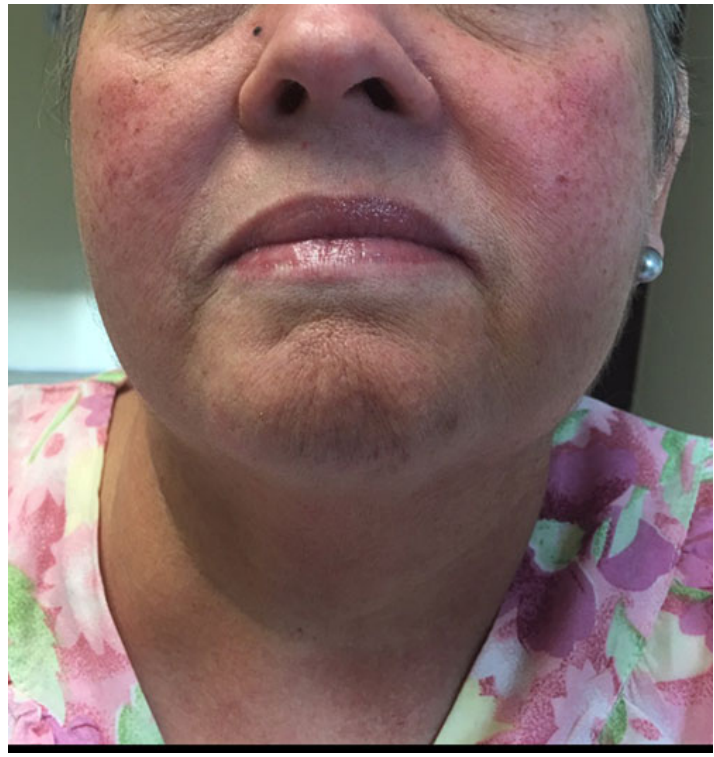

Figure 2 .

\section{Discussion}

The underlying cause of RMS, due to vancomycin, has been attributed to direct activation of mast cells rather than from anaphylactic reactions [2]. Although it is rarely life-threatening, it can lead to cardiovascular collapse due to histamine release. RMS is a reaction that occurs with the rapid parenteral administration of vancomycin however, RMS has also being described with vancomycin given via oral route and when used in powder form [3]. It has been hypothesized that severe inflammation of the gastrointestinal tract may facilitate the absorption of otherwise poorly absorbable drugs like vancomycin [3,4,5,6,7]. Accumulating evidence suggests an association between renal dysfunction and the potential risk of systemic absorption of enteral vancomycin, where it should not normally occur [3,8]. However, cases of RMS with oral vancomycin has been documented despite normal renal function [9]. These cases were seen in patients receiving vancomycin as a treatment of Clostridium difficile infection. Recently, the guidelines to treat CDI recommend oral vancomycin as the treatment of choice, which may lead to an increased number of cases of RMS after oral vancomycin [10]. In conclusion, the administration of oral vancomycin may also pose a risk of systemic side effects such as RMS. Further research is needed to characterize the exact pathogenesis of RMS occurring after oral vancomycin.

This case was presented at American College of Gastroenterology Annual Scientific Meeting in Philadelphia on October, 2018.

http://gi.org/cme-moc-and-meetings/cme-missionstatement/outstanding-poster-presenter-awards/

Outstanding Poster Presenter Awards P0178.

\section{Acknowledgements}

This work is supported in part by Dr. Moro O. Salifu's efforts through NIH Grant \# S21MD012474.

\section{References}

[1] Sivagnanam S, Deleu D. Red man syndrome. Crit Care. 2002; 7(2): 119-20.

[2] Weller, Peter. "Vancomycin Hypersensitivity.” Edited by Franklin Adkinson Jr. and Anna M Feldweg, UpToDate, 2018, www.uptodate.com/contents/vancomycin-hypersensitivity\#H2.

[3] Bailey P, Gray H. An elderly woman with 'Red Man Syndrome' in association with oral vancomycin therapy: a case report. Cases J. 2008; $1: 111$.

[4] Rao S, Kupfer Y, Pagala M, et al. Systemic absorption of oral vancomycin in patients with Clostridium difficile infection. Scand J Infect Dis 2011; 43: 386.

[5] Bergeron L, Boucher FD. Possible red-man syndrome associated with systemic absorption of oral vancomycin in a child with normal renal function. Ann Pharmacotherapy 1994; 28 : 581.

[6] Phillippa Bailey. An elderly woman with 'Red Man Syndrome' in association with oral vancomycin therapy: a case report. Cases J. 2008; $1: 111$.

[7] Aradhvula S, Manian FA, Hafidh SA, Bhutto SS. Significant absorption of oral vancomycin in a patient with clostridium difficile colitis and normal renal function. South Med J. 2006; 99: $518-20$.

[8] McCullough JM, Dielman DG, Peery D. Oral vancomycininduced rash: case report and review of the literature. DICP. 1991; 25: 1326-8.

[9] Baumgartner LJ, Brown L, Geier C. Hypersensitivity reaction following administration of low-dose oral vancomycin for the treatment of Clostridium difcile in a patient with normal renal function. J Pharm Pract. 2017; 30: 650-2.

[10] L Clifford McDonald, Dale N Gerding, Stuart Johnson, Johan S Bakken, Karen C Carroll, Susan E Coffin, Erik R Dubberke, Kevin W Garey, Carolyn V Gould, Ciaran Kelly, Vivian Loo, Julia Shaklee Sammons, Thomas J Sandora, Mark H Wilcox; Clinical Practice Guidelines for Clostridium difficile Infection in Adults and Children: 2017 Update by the Infectious Diseases Society of America (IDSA) and Society for Healthcare Epidemiology of America (SHEA), Clinical Infectious Diseases, Volume 66, Issue 7, 19 March 2018, Pages e1-e48. 